\title{
PROSPEK PENGEMBANGAN PALA (Myristica fragrans Houtt) DI HUTAN RAKYAT
}

\section{EVA FAUZIYAH*, DEVY PRIAMBODO KUSWANTORO, \& SANUDIN}

\author{
Balai Penelitian Teknologi Agrofrestry
}

Jl. Raya Ciamis, Banjar KM.4, Ciamis 46201

*Email: fauziyah_eva@yahoo.com

\begin{abstract}
The private forest is largely managed with agroforestry pattern. Nutmeg (Myristica fragrans) is a plant that has been developed in the private forest. This study aimed to determine the prospect of nutmeg in the private forest. This research was conducted in the Kemawi village, Somagede Subdistrict of Banyumas District, Central Java Province in June to July 2012. Data were collected through secondary data study, open and in-depth interviews. Twenty farmers who planted nutmeg were selected with purposive sampling technique. The obtained data were processed and analyzed descriptively. The results showed that nutmeg had a good prospect as one of the plantation species for private forest development in Kemawi village because of these several factors: 1) Kemawi land was biophysically suitable for nutmeg plantation, 2) socially, many farmers had been planting nutmeg in their land, 3) economically, nutmeg had a good and stable price that can provide additional income, 4) marketing of both fruit and seed of nutmeg were very easy, and 5) there were good attentions from the government to the nutmeg development program from production to post-harvesting process.
\end{abstract}

Keywords: nutmeg, private forest, prospect, Kemawi Village, agroforestry.

\section{INTISARI}

Hutan rakyat sebagian besar dikelola secara agroforestri. Salah satu jenis tanaman yang banyak dikembangkan di hutan rakyat adalah pala (Myristica fragrans). Penelitian ini bertujuan untuk mengetahui prospek pengembangan pala di lahan hutan rakyat. Penelitian dilakukan di Desa Kemawi, Kecamatan Somagede, Kabupaten Banyumas, Jawa Tengah pada bulan Juni sampai dengan Juli 2012. Pengumpulan data dilakukan melalui penelusuran data sekunder, wawancara terbuka dan mendalam. Narasumber dipilih secara sengaja (purposive sampling) yaitu petani yang menanam pala di lahannya sebanyak 20 orang. Data yang diperoleh kemudian diolah dan dianalisis secara deskriptif. Hasil penelitian menunjukkan bahwa pala memiliki prospek yang baik sebagai salah satu jenis tanaman untuk pengembangan hutan rakyat di Desa Kemawi karena terdapat faktor-faktor yang mendukung pengembangannya yaitu :1) lahan secara bio fisik sesuai untuk pertumbuhan tanaman pala, 2) secara sosial dapat diterima oleh masyarakat karena jauh sebelumnya sudah banyak petani yang membudidayakan pala di lahannya 3) secara ekonomi memiliki harga yang cukup tinggi dan stabil sehingga memberikan tambahan pendapatan, 4) kondisi pemasaran baik buah maupun bibitnya sangat mudah, dan 5) perhatian pemerintah terhadap pengembangan pala pada tingkat produksi hingga pengolahan pasca panen cukup besar yang telihat dari adanya beberapa program yang berkaitan dengan pengembangan tanaman pala di wilayah ini.

Kata kunci: pala, hutan rakyat, prospek, Desa Kemawi, agroforestri. 


\section{PENDAHULUAN}

Hutan rakyat adalah hutan yang tumbuh di atas tanah milik rakyat, dengan jenis tanaman kayukayuan, yang pengelolaannya dilakukan sepenuhnya oleh pemiliknya (Awang et al., 2001). Hutan rakyat lebih banyak dikembangkan oleh masyarakat dengan pola tanam campuran atau agroforestri daripada pola monokultur (Hardjanto, 2003). Hal ini dikarenakan pada umumnya kepemilikan lahan yang terbatas, sebagaimana dikemukakan Awang et al. (2001) bahwa kepemilikan lahan di Pulau Jawa sangat terbatas yaitu sekitar 0,25 ha per keluarga. Tentunya pemilihan jenis tanaman yang mempunyai nilai ekonomi tinggi dan kecocokan dengan kondisi biofisik menjadi pertimbangan petani dalam mengelola lahannya agar hutan rakyat memberikan pendapatan yang tinggi. Salah satu jenis tanaman yang dapat dikembangkan di hutan rakyat adalah pala (Myristica fragrans Houtt).

Pala merupakan tanaman rempah asli Maluku (Purseglove et al., 1995) dan telah diperdagangkan dan dibudidayakan secara turun-temurun dalam bentuk perkebunan rakyat di sebagian besar Kepulauan Maluku (Bastaman, 2008). Pala mempunyai nilai ekonomi yang tinggi (Rodianawati et al., 2015) dan memegang peranan yang sangat penting bagi perekonomian masyarakat di berbagai wilayah terutama yang berada di Kawasan Timur Indonesia. Selain sebagai produsen pala terbesar di dunia, Indonesia juga menjadi pemasok kebutuhan pala terbesar di dunia dengan pangsa mencapai 60-75 $\%$ kebutuhan dunia (Hasibuan et al., 2010; Rodianawati et al., 2015; Nurdjannah, 2007).

Pengembangan pala sebagai salah satu tanaman di hutan rakyat dapat menjadi salah satu sumber pendapatan petani. Pola agroforestri yang selama ini dilakukan oleh petani menjadi pola yang cocok karena pala memerlukan tanaman penaung pada masa pertumbuhannya untuk melindungi dari paparan sinar matahari dan angin yang berlebihan (Departemen Pertanian, 1986). Kajian ini menganalisis prospek pengembangan pala di hutan rakyat dengan studi kasus di Desa Kemawi, Kecamatan Somagede, Kabupaten Banyumas, Provinsi Jawa Tengah pada bulan Juni sampai dengan Juli 2002.

\section{BAHAN DAN METODE}

\section{Pengambilan Sampel}

Narasumber yang menjadi unit penelitian adalah petani hutan rakyat dengan jumlah sebanyak 20 orang. Pengambilan contoh dilakukan secara sengaja (purposive sampling) yaitu petani hutan rakyat yang juga menanam pala di lahannya.

\section{Pengumpulan dan Analisis Data}

Pengumpulan data dilakukan melalui penelusuran pustaka, wawancara terstruktur dan wawancara terbuka. Data yang diperoleh diolah dengan tabulasi dan dianalisis secara deskriptif.

\section{HASIL DAN PEMBAHASAN}

\section{Pengelolaan Hutan Rakyat}

Desa Kemawi merupakan salah satu dari 9 desa yang ada di Kecamatan Somagede, Kabupaten Banyumas yang terletak sekitar $29 \mathrm{~km}$ dari ibukota Kabupaten Banyumas. Jumlah penduduk Desa Kemawi pada tahun 2012 sebanyak 4.928 jiwa (1.335 KK) yang terdiri dari 2.426 laki-laki dan 2.502 perempuan dengan jumlah rata-rata jumlah anggota keluarga 3,7 jiwa dan kepadatan penduduk 509,09 jiwa/km² (BPS Kabupaten Banyumas, 2013). Rata-rata narasumber berumur 43 tahun yang termasuk ke dalam usia produktif, hal ini menunjukkan bahwa hutan rakyat merupakan sektor yang menarik bagi masyarakat. Menurut BPS Banyumas (2013) jumlah umur produktif masyarakat 
Desa Kemawi (usia 15-64 tahun) mencapai 64,3\% dengan rasio jenis kelamin $96,4 \%$ dan $48,4 \%$ mempunyai pekerjaan di bidang pertanian (hutan rakyat). Rata-rata narasumber mempunyai tingkat pendidikan SMP dengan jumlah tanggungan keluarga sebanyak 3 orang.

Kondisi penggunaan tanah di Desa Kemawi yang sebagian besar berupa lahan kering seperti terlihat pada Tabel 1 menyebabkan sebagian besar masyarakatnya memiliki mata pencaharian sebagai petani kebun/hutan rakyat dengan rata-rata pengalaman usaha tani narasumber selama 19 tahun. Kepemilikan lahan hutan rakyat narasumber berkisar antara 0,25 1,5 ha yang sebagian besar dikelola secara agroforestri dengan rata-rata kepemilikan lahan seluas 0,58 ha.

Tabel 1. Penggunaan lahan di Desa Kemawi

\begin{tabular}{lrc}
\hline Penggunaan lahan & Luas (ha) & Persentase (\%) \\
\hline Sawah tadah hujan & 3,63 & 0,37 \\
Pekarangan/bangunan & 105,7 & 10,92 \\
Tegal/kebun & 821,84 & 84,87 \\
Kolam & 0,8 & 0,08 \\
Lain-lain & 36,36 & 3,75 \\
\hline Jumlah & 968,33 & 100 \\
\hline
\end{tabular}

Sumber: BPS Kabupaten Banyumas (2011).

Ada beberapa pola tanam hutan rakyat yang ditemui di desa ini di antaranya: 1) tanaman kayu + tanaman perkebunan, 2) tanaman kayu + tanaman buah + tanaman perkebunan, 3) tanaman kayu + tanaman buah + tanaman perkebunan + tanaman obat, dan 4) tanaman kayu + tanaman buah + tanaman perkebunan + tanaman obat + tanaman semusim. Jenis kayu yang dominan di desa ini adalah sengon, sementara tanaman perkebunan adalah cengkeh, kelapa, kopi, dan pala, dan tanaman obat adalah kapulaga dan jahe. Beberapa pertimbangan petani dalam memilih jenis sengon sebagai tanaman yang dominan diantaranya adalah kayunya lebih cepat menghasilkan dengan daur 5 tahun, bibit mudah diperoleh baik dengan cara membeli dari penjual keliling atau dari anakan alami, dan mudah dijual.

Kegiatan pemeliharaan yang dilakukan pada hutan rakyat di antaranya adalah penyiangan dan pemupukan. Berdasarkan hasil wawancara diketahui bahwa $75 \%$ narasumber melakukan kegiatan pemupukan menggunakan pupuk kandang, namun hanya $35 \%$ narasumber yang menggunakan pupuk kimia selain pupuk kandang, hal ini disebabkan karena alasan modal yang terbatas. Keterbatasan modal juga menjadi alasan petani tidak melakukan penyemprotan menggunakan bahan kimia terhadap serangan hama dan penyakit seperti karat puru, ulat tanah, dan ulat daun. Petani hanya menebang pohon yang terkena hama dan penyakit tersebut kemudian dijual.

Kegiatan pemanenan yang dilakukan oleh petani hutan rakyat dilakukan dengan sistem tebang pilih atau tebang butuh. Dengan cara ini petani memilih beberapa tegakan berdasarkan kriteria diameter yang telah mencapai ukuran diameter tertentu, walaupun belum masak tebang atau dilakukan pada pohon yang terkena serangan hama dan penyakit. Kegiatan penebangan dilakukan oleh pihak pembeli atau pedagang pengumpul (bandar) secara borongan dengan alasan mudah dan tidak merepotkan, hanya $20 \%$ narasumber yang melakukan penebangan sendiri.

Desa Kemawi merupakan salah satu desa yang memiliki hasil kelapa, karet, cengkeh, dan pala yang cukup besar (BPS Kabupaten Banyumas, 2013). Berdasarkan hasil pengamatan lapangan diketahui bahwa selain kayu, hasil dari gula kelapa merupakan salah satu andalan dari masyarakat di desa ini. Untuk tanaman selain kayu, sistem pemasaran yang dilakukan adalah dengan cara dijual langsung ke pasar dan 
pembeli datang ke rumah untuk membeli hasil produknya.

Untuk memenuhi kebutuhan jangka pendek (harian) maupun jangka panjang (bulanan/tahunan) masyarakat diperoleh dari hasil kebun (hutan rakyat), karena hampir sebagian besar masyarakat tidak memiliki sawah. Widya (2007) menyebutkan masyarakat memenuhi kebutuhan hariannya dari hasil penjualan gula kelapa dan juga pekarangan, sementara kebutuhan lain yang lebih besar seperti biaya sekolah, kesehatan, pemeliharaan rumah, dan investasi dipenuhi dari hasil menjual tanaman palawija, tanaman obat, tanaman buah-buahan dan tanaman kayu. Berdasarkan hasil wawancara diketahui bahwa rata-rata rata pendapatan narasumber sebesar Rp 19.100.199 per tahun atau Rp 1.591 .683 per bulan.

\section{Prospek pengembangan pala di hutan rakyat}

Petani di Desa Kemawi sudah mulai mengembangkan pala sebagai tanaman multi-purpose trees (MPTs) di hutan rakyat (Gambar 1) dengan alasan prospeknya cukup baik dilihat dari harga dan produktivitas yang dihasilkan lahan di desa ini. Beberapa aspek yang mendukung pengembangan pala di Desa Kemawi sebagai berikut:

\section{Aspek biofisik}

Pala membutuhkan iklim panas dengan curah hujan yang tinggi dan merata/tidak banyak berubah sepanjang tahun dengan suhu udara lingkungan sekitar $20-30{ }^{\circ} \mathrm{C}$. Pala juga termasuk jenis tanaman yang tahan terhadap musim kering selama beberapa bulan dan membutuhkan tanah gembur dan subur, sangat cocok pada tanah vulkanis serta memiliki drainase yang baik (Hatta, 1993). Masih menurut Hatta (1993), pala tumbuh baik pada tanah yang bertekstur pasir sampai lempung, kandungan bahan organik yang tinggi, $\mathrm{pH}$ antara 5,5 - 6,5, dan mempunyai ketinggian 500-700 m dpl.

Desa Kemawi terletak pada ketinggian $500 \mathrm{~m}$ dpl dengan curah hujan $2.000 \mathrm{~mm} / \mathrm{tahun}$, jumlah bulan hujan sebanyak 6 bulan dengan suhu rata-rata $21,7^{\circ} \mathrm{C}$ (BPS Kabupaten Banyumas, 2013). Beberapa faktor biofisik yang menjadikan tanaman pala banyak ditanam oleh petani hutan rakyat di Desa Kemawi diantaranya adalah tanaman pala dapat tumbuh baik bahkan pada tanah yang miskin hara jika dimbangi dengan pemupukan yang baik. Tanaman pala juga membutuhkan pelindung dalam pertumbuhannya, sehingga penanaman bersama tanaman kayu atau tanaman lainnya di hutan rakyat sangat sesuai. Tanaman pelindung ini diperlukan karena pala sangat peka terhadap angin kencang.

\section{Aspek Sosial}

Selain sesuai dari kondisi biofisik, pengembangan jenis tanaman di suatu daerah juga harus disukai oleh masyarakat. Pala merupakan jenis tanaman yang

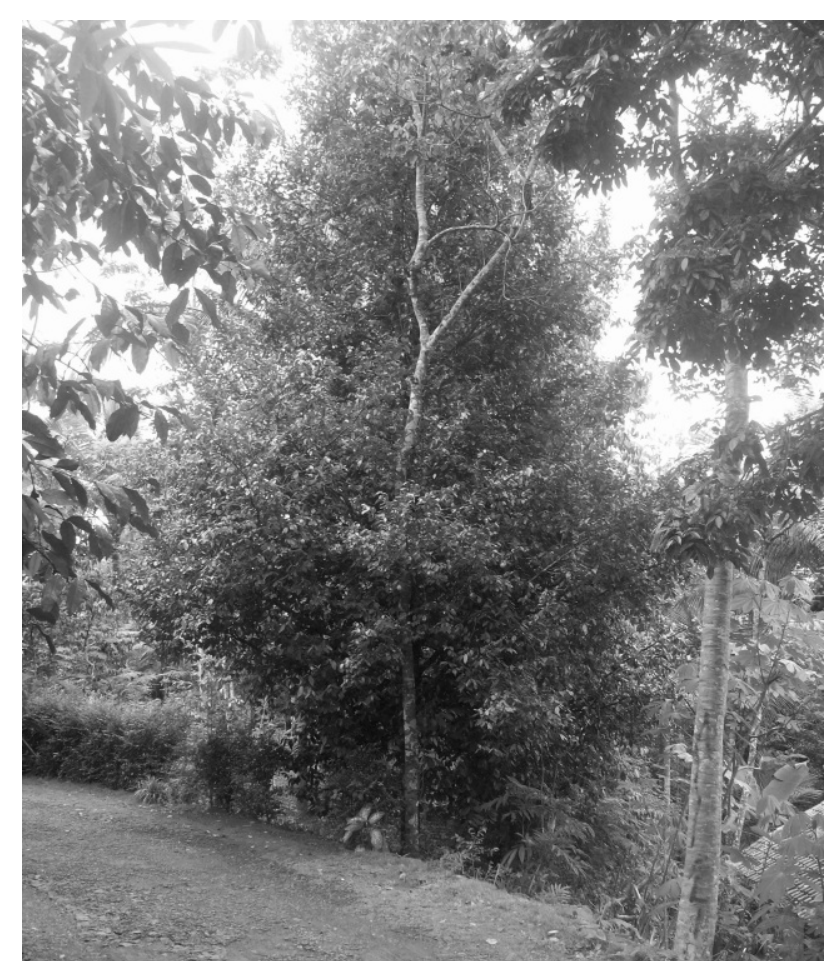

Gambar 1. Pohon pala di kebun milik petani di Desa Kemawi 
sudah lama dikenal di Desa Kemawi, sehingga secara sosial pengembangan pala diterima oleh masyarakat setempat. Petani juga mempunyai tingkat pengetahuan yang baik dalam budidaya pala mulai dari pembibitan sampai pemanenan.

Pengetahuan tersebut diperoleh baik secara otodidak maupun hasil kegiatan penyuluhan yang dilakukan oleh penyuluh yang rutin melakukan penyuluhan tiap bulan. Sebanyak 4 orang narasumber petani di Desa Kemawi sudah bisa membibitkan pala dan menjualnya dengan harga tergantung ukuran dan jumlah daun dimana untuk tinggi bibit 20 $\mathrm{cm}$ dijual Rp 1.800, tinggi $30 \mathrm{~cm}$ (Rp 2.700), tinggi

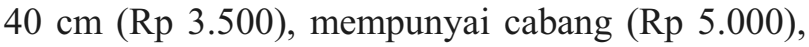
dan untuk bibit yang sudah mempunyai daun 3 buah dijual Rp 18.000.

\section{Aspek ekonomi}

Pala sudah menyebar ke seluruh wilayah Indonesia, daerah penghasil utama pala di Indonesia adalah Maluku, Papua, Sulawesi Utara, Nangroe Aceh Darusalam, Sumatera Barat, dan Jawa Barat (Direktorat Jenderal Perkebunan, 2010). Produksi pala Indonesia meningkat dari 16 ribu ton pada tahun 2009 menjadi 25,8 ribu ton pada tahun 2013 yang berasal dari perkebunan rakyat yang luasannya mencapai 140 ribu ha pada tahun 2013 (BPS
Republik Indonesia, 2014). Permintaan dari luar negeri adalah dari biji, fuli, dan minyak pala, sedangkan kebutuhan di dalam negeri akan daging buah dan produk olahan pala juga dapat menjadi kegiatan bernilai ekonomi yang dapat meningkatkan kesejahteraan masyarakat.

Pala menghasilkan dua produk bernilai ekonomi tinggi yaitu biji pala dan fuli atau kembang pala yang menyelimuti biji (Gambar 2). Kedua produk ini menghasilkan minyak atsiri yang dapat digunakan sebagai bahan baku industri minuman, obat-obatan dan kosmetik (Bustaman, 2007).

Selain nilai ekonomi pala yang cukup tinggi, peluang pasar pala dan turunannya juga masih terbuka lebar. Indonesia merupakan pemasok utama biji pala dan produk turunannya untuk pasar Amerika Serikat, Inggris, dan Jerman. Kekurangan kebutuhan di negara tersebut dipasok oleh Grenada dan Sri Lanka (Bastaman, 2008; Rodianawati et al., 2015).

Petani di Desa Kemawi sangat tertarik untuk mengembangkan pala karena pala memiliki nilai ekonomi yang sangat tinggi. Pala dapat dipanen mulai umur 7 - 9 tahun sampai umur 25 tahun dimana dapat menghasilkan buah sepanjang tahun. Menurut Hidayah (2005), pada umur 7 tahun pala sudah dapat

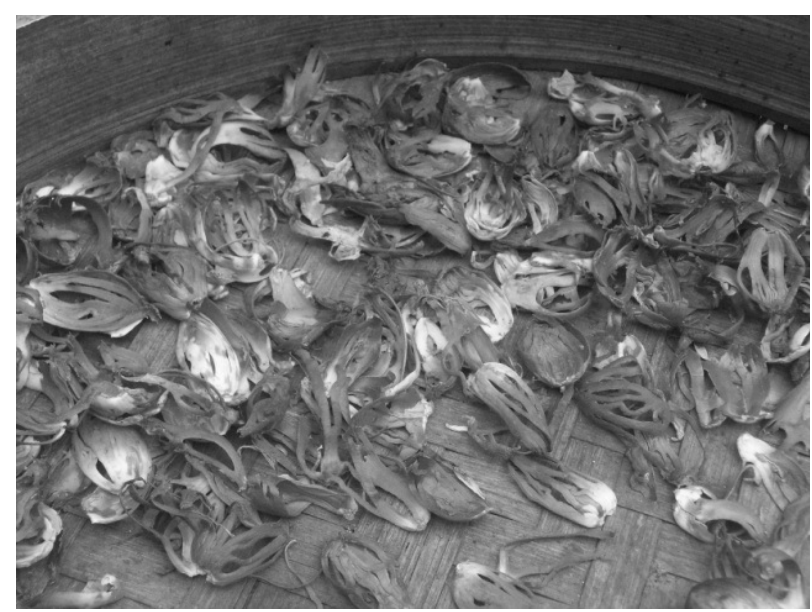

Gambar 2. Biji pala dan fuli yang sedang dijemur 
menghasilkan buah, dengan tingkat produksi $90 \mathrm{~kg}$ biji pala dan $21 \mathrm{~kg}$ fuli pala per ha.

\section{Kondisi lingkungan pemasaran}

Pemasaran pala belum tertata dalam suatu sistem, belum ada kelembagaan (koperasi) yang menanganinya. Petani bebas menjual pala yang dihasilkan kepada pedagang pengumpul di desa atau di kota kecamatan. Selanjutnya pedagang pengumpul kecamatan menjual pala ke pedagang di kota kabupaten atau provinsi. Sistem pemasaran seperti ini menyebabkan harga pala di tingkat petani menjadi rendah. Transportasi merupakan kendala utama dalam pemasaran pala sehingga biaya usaha tani menjadi tinggi (Bastaman, 2007).

Petani di Desa Kemawi menjual pala dalam bentuk kering maupun dalam bentuk basah jika terdesak kebutuhan dan belum ada yang menjual dalam bentuk olahan dengan alasan kemudahan sehingga nilai tambah yang diperoleh petani masih rendah. Keuntungan yang diperoleh dari penjualan pala dalam bentuk basah jelas lebih rendah dibandingkan pala kering (Hidayati, 2011).

Petani di Desa Kemawi menjual pala ke tengkulak di tempat tinggalnya atau ke tengkulak di dalam desa, dan/atau langsung menjual ke toko rempah-rempah. Namun biasanya tengkulak yang mendatangi petani untuk membeli pala. Kondisi ini sangat membantu petani dalam menjual hasil kebunnya, namun di sisi lain kadangkala harga yang diterima petani lebih rendah dari harga pasar. Proses jual-beli dilakukan secara sendiri-sendiri oleh petani meskipun petani tergabung dalam kelompok tani, sehingga petani hanya mendapatkan informasi harga dari tengkulak.

Fitrina (2007) menyatakan bahwa pala merupakan komoditi yang memerlukan pengolahan lanjutan sehingga lembaga pemasaran sangat penting membantu hingga sampai kepada konsumen. Secara umum kondisi pemasaran di wilayah Kecamatan Somagede sangat mendukung berkembangnya berbagai hasil dari hutan rakyat termasuk pala. Pada Tabel 2 disajikan kondisi lingkungan pemasaran produk hasil hutan bukan kayu khususnya pala.

5. Dukungan pemerintah

Pemerintah Daerah (Pemda) Kabupaten Banyumas memiliki perhatian yang cukup besar terhadap pengembangan hutan rakyat. Selain pengembangan kayu, Pemda Kabupaten Banyumas mendorong pengembangan HHBK dalam upaya meningkatkan pendapatan dari hutan rakyat. Dukungan Kabupaten Banyumas dapat dilihat dari berbagai program yang diluncurkan termasuk pala di Kecamatan Somagede khususnya Desa Kemawi seperti disajikan pada Pada Tabel 3.

Desa Kemawi merupakan salah satu desa yang dianggap memiliki kondisi fisik yang cocok dengan pala, sehingga Pemerintah Kabupaten Banyumas

Tabel 2. Kondisi pemasaran pala di Desa Kemawi Kecamatan Somagede

\begin{tabular}{ll}
\hline Kondisi pemasaran & \multicolumn{1}{c}{ Uraian } \\
\hline Bagian pala yang dijual & biji pala, fuli, bibit pala \\
di tempat petani atau pedagang pengumpul (tengkulak) \\
Tempat menjual & dalam desa/kecamatan, toko rempah-rempah \\
Asal pembeli (tengkulak) & Pedagang pengumpul dari desa dan luar \\
Bentuk transaksi & Tunai \\
Sifat penjualan & Temporer \\
Status pembeli & Pedagang \\
\hline
\end{tabular}

Sumber : Data primer (2012) 
Tabel 3. Program-program yang berkaitan dengan hutan rakyat di Kecamatan Somagede Kabupaten Banyumas

\begin{tabular}{ll}
\hline Jenis kayu dominan & Sengon \\
\hline Jenis tanaman non kayu dominan & Cengkeh, pala, kopi, kelapa, kapulaga \\
\hline Program dan asal instansi & - Gerhan dari Distanhutbun Banyumas \\
& - Bantuan bibit pala, manggis, durian dan sengon dari \\
& Distanhutbun Banyumas \\
& - Bantuan alat penyulingan pala \\
& - Pelatihan pengolahan daging pala dari Universitas Jenderal \\
& Soedirman Purwokerto \\
\hline Sasaran & Meningkatkan nilai tambah pala \\
\hline
\end{tabular}

Sumber : Data primer diolah (2012).

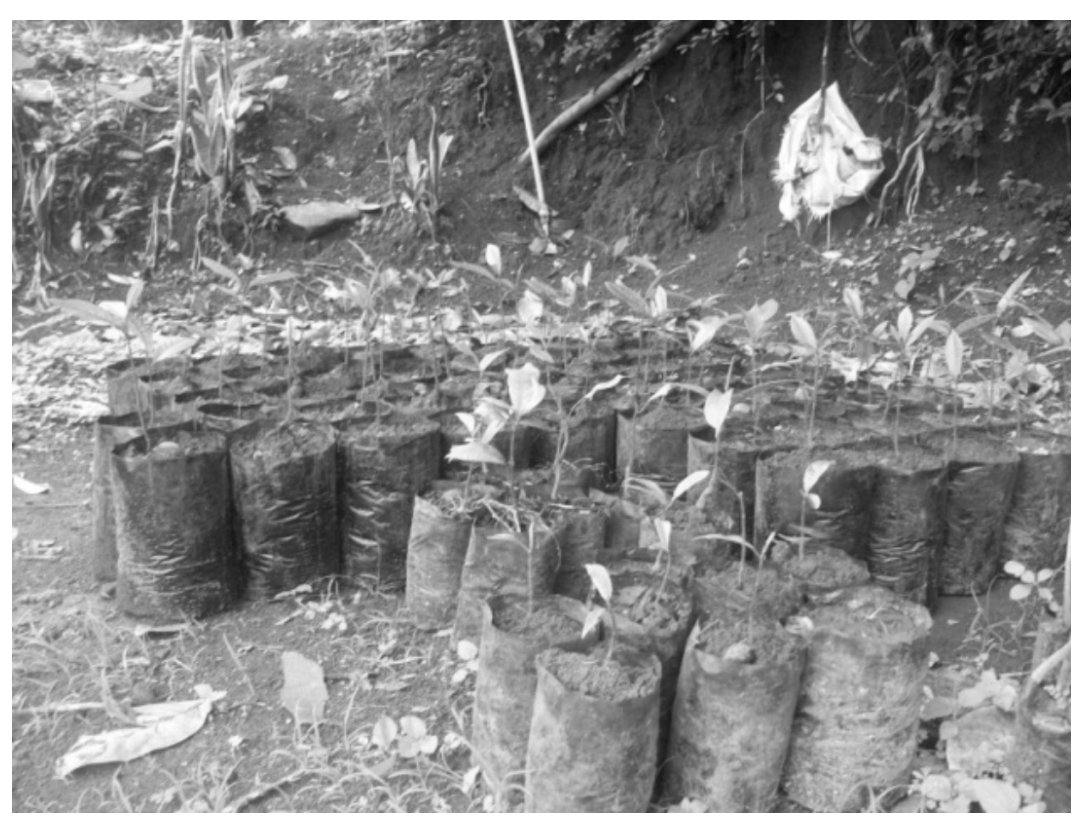

Gambar 3. Pembibitan pala milik salah satu petani di Desa Kemawi

melalui Dinas Pertanian Kehutanan dan Perkebunan dan juga Dinas Perindustrian dan Perdagangan memberikan bantuan untuk pengembangan pala berupa bibit, penyuluhan tentang pembibitan, dan bantuan alat penyulingan minyak pala. Semua narasumber menyatakan bahwa bantuan yang diberikan tersebut sangat bermanfaat dan hasilnya sudah mulai dapat dirasakan seperti pembibitan pala (Gambar 3) yang sudah mulai memberikan pendapatan tambahan.
KESIMPULAN

Pala memiliki prospek yang baik untuk dikembangkan di hutan rakyat di Desa Kemawi karena terdapat faktor-faktor yang mendukung pengembangannya, yaitu :1) secara fisik memiliki kesesuaian dengan pertumbuhan tanaman pala, 2) secara sosial dapat diterima oleh masyarakat karena sebelumnya sudah banyak petani yang membudidayakan pala di lahannya 3) secara ekonomi memiliki harga yang cukup tinggi dan stabil sehingga memberikan tambahan pendapatan, 4) kondisi pemasaran baik buah maupun bibitnya sangat 
mudah, dan 5) perhatian pemerintah terhadap pengembangan pala pada tingkat produksi hingga pengolahan pasca panen cukup besar. Namun demikian, masih diperlukan upaya dari berbagai pihak baik pada tingkat produksi maupun pasca panennya agar pala di Desa Kemawi dapat memenuhi kebutuhan dalam skala yang lebih besar dan dapat berkontribusi lebih banyak dalam peningkatan pendapatan petani.

\section{DAFTAR PUSTAKA}

Awang SA, Santoso H, Widayati WT, Kustomo YN, \& Supardiono. 2001. Gurat Hutan Rakyat di Kapur Selatan. Debut Press. Yogyakarta.

Bastaman S. 2007. Prospek dan strategi pengembangan pala di Maluku. Balai Besar Pengkajian dan Pengembangan Teknologi Pertanian, Bogor.

Bastaman S. 2008. Prospek pengembangan minyak pala banda sebagai komoditas ekspor Maluku. Jurnal Litbang Pertanian 27(3), 93-98.

BPS Kabupaten Banyumas. 2013. Kecamatan Somagede dalam Angka 2012. Banyumas.

BPS Republik Indonesia. 2014. Statistik Indonesia 2014. Jakarta.

Departemen Pertanian. 1986. Pala dan Pengolahannya. Bagian Proyek Informasi Pertanian Irian Jaya.

http://pustaka.litbang.pertanian.go.id/agritek/ppu a0158.pdf. Diakses tanggal 1 November 2014. 11.00 WIB.

Direktorat Jenderal Perkebunan. 2010. Daerah sumber tanaman pala di Propinsi Jawa Barat. Jakarta.

Fitrina. 2007. Analisis Saluran Pemasaran Komoditas Pala (Myristica fragran HOUTT) dan Turunannya : Studi Kasus Desa Tamansari Kecamatan Kabupaten Bogor. Skripsi (Tidak Dipublikasikan). Fakultas Pertanian IPB, Bogor.

Hardjanto. 2003. Keragaan dan Pengembangan Usaha Kayu Rakyat di Pulau Jawa. Disertasi (Tidak Dipublikasikan). Program Pasca Sarjana IPB, Bogor.

Hasibuan AM, Sudjarmoko B \& Listyati D. 2012. Analisis keunggulan komparatif dan kompetitif usahatani pala (Studi kasus: Kabupaten Bogor dan Sukabumi). Buletin RISTRI 3(3), 223-230.
Hatta S. 1993. Budidaya Pala Komoditas Ekspor. Yogyakarta.

Hidayah I. 2005. Analisis kelayakan finansial usahatani tanaman perkebunan rakyat di Kabupaten Buru. Prosiding. Balai Pengkajian Teknologi Pertanian, Maluku.

Hidayati R. 2011. Perbandingan Pendapatan dan Keuntungan Petani Pala (Myristica fragran Haitt) antara Penjualan dalam Bentuk Basah dan Kering di Kecamatan Tanjung Raya Kabupaten Agam. Skripsi (Tidak Dipublikasikan). Fakultas Pertanian Universitas Andalas, Padang.

Nurdjannah N. 2007. Teknologi Pengolahan Pala. Balai Besar Penelitian dan Pengembangan Pascapanen Pertanian, Badan Penelitian dan Pengembangan Pertanian, Bogor.

Purseglove JW, Brown EG, Green SL, \& Robbins SRJ. 1995. Spices. Longmans, New York. 175-228.

Rodianawati I, Hastuti P, \& Cahyanto MN. Nutmeg's (Myristica fragrans Houtt) oleoresin: effect of heating to chemical compositions and antifungal properties. The First International Symposium on Food and Agro-biodiversity (ISFA2014). Procedia Food Science 3, 244-254.

Widya K. 2007. Permasalahan Pemasaran Produk Pertanian Banyumas: Studi Kasus Desa Kemawi Kecamatan Somagede.

Tegalan-online.blogspot.com/2007/02/permasala han-pemasaran-produk-pertanian.html. Diakses tanggal 1 November 2014. 09.00 WIB. 